\title{
Present situation and Countermeasures of rural sports in China
}

\author{
SUN Yang ${ }^{1, \text { a }}$, MA Yuehong ${ }^{2}$ \\ 1,2 HEILONGJIANG UNIVERSITY OF TECHNOLOGY, Jixi 158100,China \\ ajxdxtyylx@163.com
}

Keywords: Rural sports; peasant family; current situation of small town; countermeasure; system design

\begin{abstract}
Sports first is the survival and development of human needs. As an important part of China's sports, rural sports in China's "sports law", "National Fitness Program" has a clear requirement. Enhance the physical quality of farmers, improve the quality of life of farmers, to achieve the modernization of rural society is the problem of building a well-off society in an all-round way. However, the theory and practice of rural sports in China is relatively backward, as a sports worker, it is the responsibility of the efforts, so the research paper came into being. In this study, through the perspective of China's rural sports current situation and put the emphasis on the status of rural sports as the breakthrough point, the torsion of the backward situation of rural sports as the main line to play the comparative advantages of rural sports as a breakthrough in the study, the use of theoretical thinking, take effective measures, strengthen and improve the work of rural sports. The main research object is the theory and practice of sports activities in rural areas. Using the methods of literature, field visits, expert interviews and other research methods, from the history to the future, from the traditional to modern, from the concept of value to the activities of the specific content of the study.
\end{abstract}

\section{Introduction}

Rural sports is an integral part of sports in china. Rural sports, which has a long history, rich in content, in the long history of China occupies a place. Is closely related to the status of rural sports development and rural society, economy and culture, the development of rural socio-economic and cultural requirements in line with the rural sports. In recent years, farmers responsible for fitness, recreation and increasing the role of material civilization and spiritual civilization of sports demand. Study on rural sports become inevitable. Through research on the development of rural sports, can grasp the pulse of the rural economic, social and cultural development, understand the farmers' living conditions, proceed from reality, formulate a series of farmers sake, for services to the rural sports policies and measures, to narrow the differences between urban and rural sports, promoting China's sports career to a new level, to proposed in the report of 16th National Congress of comprehensive construction of well-off society and. American Rural sociologist Rogers once said that a country to develop[1], we must study the farmers, lack of understanding of the farmers is the cause of many development planning failure. With the deepening of our market economy and social democratization process accelerate, in the new century to joint, cooperative, organization, coordination characteristics of the scale management of agriculture, industrial management mode of production has achieved initial appearance end, increase the income of the farmers, rich consumer data, lifestyle changes, enhance the awareness of equality, competition, communication, open, resulting in "engage in the original rural sports methods that would be difficult to work, we must strengthen the rural areas and farmers sports research, innovative methods, in service to the farmers, service to the society. China is a developing country with the economic construction as the center, the rural area is vast, the regional development is extremely unbalanced, the rural sports present situation is different, which forms the diversity and complexity of the rural sports. Study of rural sports to use advanced theory and new thinking, from macroscopical to microcosmic, from the whole to the individual cycle to summarize and explore its characteristics and rules, from rural sports history, current situation and future peep its activity mechanism, content and mode, to meet the farmers need to create, adapt to rural development, 
promote agricultural modernization and sports socialization process of rural sports in new situation[2].

Due to historical reasons, the relative backwardness of rural sports in China has become an indisputable fact. The study of rural sports, thus better carry out rural sports activities, enrich the cultural life of rural sports is the embodiment of the superiority of the socialist system in our country, there is help to radiate the appearance and vitality of the modern new peasant, to promote rural spiritual civilization, material civilization and political civilization construction and characterization of sports front to the full implementation of the action direction of the important thought of "Three Represents". Since the reform and opening up, rapid development of rural society and economy, improving the living standards of farmers, the demand of sports culture gradually revealed, coupled with transition of the comparative advantage of rural natural environment of urban population great attraction and the rural traditional sports to modern sports, in rural sports activities appears many new situations and new problems, for the study of rural sports time has been mature. From the rural realities of through the induction of rural sports activities and comprehensive analysis and theoretical guidance to carry out the work of rural sports, do go or not less detours, and more effectively mobilize farmers to participate in sports activities, enhance the concept of sports value, for the farmer's production and living services.

\section{Overview of rural sports in China}

The concept of rural sports is the concept of the concept of physical education, rural sports participants include living in rural areas of rural population, but also includes living in the city and the exercise of the rural residents in rural areas. Therefore, the concept of rural sports should be in the rural areas, the rural population to participate in the main body of the sports activities, including the minority sports in rural areas. Compared with the classification of sports in our country, the rural sports are composed of three parts, which are rural competitive sports, rural school physical education and rural mass sports. These three aspects are different from each other in different forms, but they are connected with each other. They are all through physical activity to develop the body and enhance physical fitness, have the role of education, but also have the factors of competition. Rural sports refers to mobilize the rural population to participate in sports activities and play sports competitive function held in rural areas of high level sports activities of the various competitions, such as province, city of the peasant movement, National Peasant Games, large minority sports. In essence, the rural competitive sports is a social sport, but with the development of modern sports, the part of the rural competitive sports will be evolved into the part of competitive sports in China. The rural school physical education refers to the sports activities in the rural areas or in the agricultural schools. Rural sports is a part of our social sports that include the rural population (farmers) the men and women of all ages and injured, sick and disabled people to participate in voluntary to fitness, health, medical, gaming as a means to achieve fitness, health, rehabilitation, entertainment and leisure for the purpose of sports activities. Rural sports have broad and narrow sense, broad sense refers to rural competitive sports, rural school sports, rural mass sports in the three part of the general term, narrow sense refers to the mass sports in rural areas. This paper takes the rural mass sports as the main research object[3].

\section{The origin of rural sports}

Origin of sports in primitive ancestors in primitive hunting, gathering and other agricultural production, life, slash and burn agriculture of primitive form gave birth to the seeds, the growth and the development of sports. On the basis of the disintegration of the primitive society, the establishment of the private ownership of the means of production and the formation of the class. But different historical stage, the 'social and economic status is not the same, early farmers in many places just slave, serf, farmers or sharecroppers. They in the life of labor, gradually and the development of walking, running, jumping and throwing, climbing, swimming, wrestling and other production and life skills, and choppers, scraping, catapult, throwing device such as a production tool. The common production and life form the original rural community. Thus, the physical education in the initial state 
of agriculture, rural areas and farmers can be evolved. As early as the spring and autumn and the Warring States period, the vast majority of sports activities in our country have a prototype and record. To promote the development of rural sports, there are five main factors: first, the farmers in the production, the germination of sports activities, thousands of years enduring, spread so far. Such as swimming, swing etc.. Second, because of China's ancient wars, peasants conscripted as soldiers, in the military to many military sports, back to the countryside and to teach others, so military sports is widely spread. Such as archery, sword, etc.. The three is the sports activity as a celebration, and the formation of local customs, such as dragon boat races. The four is the other educators advocate, to exercise as the factors of education and widely respected. Five is the input of western sports and the government of the vast ancient sports activities for the collection, screening, advocacy results. Therefore, the farmer is defined from the point of view of occupational and household typically exhibit the difference between three levels. The first level is refers to the narrow sense of the farmers, means the direct or specialized in agricultural production workers, which is the traditional concept of farmers; the second level is in generalized agricultural production and business activities of the workers, them or agriculture, industry and trade, or business, but most failed and rural land completely separated, occupational status and the household registration status changes inconsistent; the third level is refers to the broad farmer, refers to the total population in rural areas. In this study, we use the concept of the most broad farmer. The rural mass sports and the farmer sports title are different, the essence is same[4].

\section{Spontaneity and seasonality of sports activities}

As a kind of collective behavior, rural sports, in addition to the performance of the organization, the leadership of the masses, often the performance of non - organization, non - Leadership spontaneous behavior. Under normal circumstances, as long as the farmers subjective love sports entertainment, you can through the members of the chain between the emotional infection, the temporary formation of sports teams to carry out sports competitions. In a sense, this kind of extensive and vivid folk spontaneity is the deep foundation of the rural sports activities. But this spontaneity does not have the continuity of time, it is subject to the constraints of the productive labor. Therefore, less in the busy season of sports, or at least is a combination of work and rest time. Only in the slack season or grand festival, sports has a wide range of social, also contributed to the spontaneous sports continuation and development. The human body is an organic whole, if after the local fatigue, the purpose of systemic activities so that the original is not chances of muscle activity, the cerebral cortex new excitement and excitement of the original work of inhibition on, then this part of the nerve cell can get sufficient rest. Physical activity can also promote the body's blood circulation, strengthen metabolism, so that the muscles to get enough oxygen and nutrients, so that the accumulation of milk. Acid to further metabolism, eliminate fatigue. Experiments have also shown that when the local muscle fatigue, appropriate systemic activity, can be recovered faster than the rest. In addition, some labor does not need organs such as the heart, lungs play great ability and sports activities such as basketball, running, swimming and so on can play the organs such as the heart, lungs, so that physical exercise on farmers also is very necessary.

\section{Thoughts on developing rural sports}

To carry out rural sports is required to adhere to the five principles, adhere to the combination of sports and health principle, it is inherent requirement of health, give full play to the role of medical and rehabilitation sports, is one of the effective ways for the vigorous development of peasant sports. Adhere to the principle of combining physical quality with personality and psychology, which is the main content of the construction of the quality of the people, is the starting point of the modernization of farmers. Adhere to the combination of sports and culture (local culture and cultural education) principles, sports and culture can not be divided into one, to form a common life of farmers. The principle of combining traditional sports and modern sports, taking the traditional sports as the foundation, and grasping the integration development of the world and oneself at the same time, is the foundation of the sustainable development of the sports of the farmers. Adhere to the urban and rural sports, regional sports integration principle, depending on the urban and rural areas is a interdependent and mutual organic whole, is high in urban and rural areas, regional combined system 
effect, promote urban and rural sports, regional sports complementary advantages, the coordinated development and common prosperity. The social transformation is based on the traditional society and the modern society, it is the transition from the traditional to the modern society. China's modernization is inseparable from the farmers' modernization, and "modernization theory generally emphasize the people's values and behavior norms play an important role in the modernization and development, emphasizing the change of values is the development of the most important prerequisite". "At this stage really a lot of people life level is not too high, but the sports feeling have only clock, active participation is very high; on the other hand, there are also quite a number of Chinese people although `quality of life 'status greatly improved, but never in any form of physical activity, the phenomenon that Ming's behavior and the sports value conception has great relationship. Therefore, the study of rural sports, the farmers should be the values of sports as a breakthrough, to explore its development.

\section{In order to change the traditional sports values of farmers as a breakthrough}

To establish a flexible and efficient rural sports investment and management mechanism to adhering to and in the service of building a well-off society in an all-round way is the central task of the party the overall situation, the more solid, in-depth implementation of the national fitness program, pay attention to in the referendum on the, work hard at the gym. To further enhance the understanding of rural sports, the sports undertakings in rural areas as one of the important tasks of building a prosperous, democratic and civilized socialist country and incorporated into the national economic construction and social development planning, as an important part of socialist spiritual civilization, material civilization and political civilization construction[5]. China's rural sports funds investment is not high, the management mechanism is not smooth is an important reason for the backward rural sports. China's rural sports is the focus of the township, but it does not mean that the main investment and management of the township government. In fact, it is difficult for the financial and sports talents of the township to have more investment and effective management, it is difficult to put the sports industry into the social development planning. To the township as the focus should be to China's large rural population, live in scattered, the focus of rural sports activities placed in the township, to the township as a leader, the villagers' committee as the basis, farmers associations as a link, forming network of radiation force. As for the rural sports investment and management of the main body is not in the township, while in the state and society. Specifically, the capital formation model of national, social, personal investment, at present to countries (including sports government departments) input mainly gradually to society (including the township), personal (including farmers) investment transfer; management lies in the country (including sports government departments) to fully mobilize the society (including the township), personal (including farmers enthusiasm to develop the sports laws, regulations, guidelines and policies, the formation of the concerted efforts of the situation. Rural areas to rely on farmers associations and cultural center, cultural and youth to carry out sports activities, townships, towns, street, village to have organization, association of sports enthusiasts, venues and facilities, physical education, sports teams, usually have activities, slack, holiday game.

\section{Conclusion}

The backwardness of rural sports is related to our country's population, weak foundation, economy, education and science and technology is not developed, but because of this, more should develop the rural sports. Using the advantages of rural traditional sports: China has a history of five thousand years of civilization, city is also from rural separated; in the countryside, Dragon Boat Festival Dragon Boat Festival, Double Ninth Festival mountaineering activities, new year of the dragon and lion dance and minority swing Chiaki, pearl ball, cricket, shot an arrow, wrestling and have a deep and broad mass base: Rural Sports colorful; and so on, in conjunction with modern sports, give full 
play to the sports functions, has important significance to promote the progress of rural areas and sports modernization.

\section{References}

[1] Qiu Jun. Structure of Chinese sports population [J]. China Sports Science and technology. 2012 (08).

[2] Wang Guanghu, Zhang Hongjian. The social problem of the vulnerable group -- the national fitness can not be avoided [J]. Journal of Chengdu Sport University (04) (2012).

[3] Chinese national traditional sports present situation and development prospect of Sichuan [J]. sports science $2012(01)$.

[4] Fan Chengling, Ge Shulin. Government intervention in the health of the whole people, on improving the level of national health, expanding sports consumption of the proposal report [J]. China Sports Science and technology, 2014 (03).

[5] Chang Sheng. The status quo and Countermeasures of physical education in some rural junior middle schools in coastal economically developed areas [J]. China Sports Science and technology. 2012 (03). 